\title{
Dynamic Active Power Control with Improved Undead-Band Droop for HVDC Grids
}

Vrana, T.K.; Zeni, Lorenzo; Fosso, O.B.

Publication date:

2012

Link back to DTU Orbit

Citation (APA):

Vrana, T. K., Zeni, L., \& Fosso, O. B. (2012). Dynamic Active Power Control with Improved Undead-Band Droop for HVDC Grids. Paper presented at 10th International Conference on AC and DC Power Transmission, Birmingham, United Kingdom.

\section{General rights}

Copyright and moral rights for the publications made accessible in the public portal are retained by the authors and/or other copyright owners and it is a condition of accessing publications that users recognise and abide by the legal requirements associated with these rights.

- Users may download and print one copy of any publication from the public portal for the purpose of private study or research.

- You may not further distribute the material or use it for any profit-making activity or commercial gain

- You may freely distribute the URL identifying the publication in the public portal

If you believe that this document breaches copyright please contact us providing details, and we will remove access to the work immediately and investigate your claim 


\title{
Dynamic Active Power Control with Improved Undead-Band Droop for HVDC Grids
}

\author{
TK Krana*, L Zeni ${ }^{\dagger}$, O B Fosso* \\ *NTNU, Norway,vrana@ntnu.no, 'DTU, Denmark
}

Keywords: HVDC, Power Converter, Active Power Control, Droop Control, Meshed DC Grid.

\begin{abstract}
The earlier developed control method using a piecewise linear droop curve, with different droop values for the different segments, has now been optimised for dynamic performance. Non-linearities at the junctions of two linear droop sections have been adressed. Also non-linearity of power based DC voltage control has been adressed. Dynamic instability due to high control gains has been treated and a new improved control structure has been proposed. The concepts have been validated with RMS simulation with the DIgSILENT PowerFactory software on the CIGRE B4 DC grid test system.
\end{abstract}

\section{Introduction}

The North Sea is likely to be the area for a first implementation of a HVDC grid [1]. As wind farm installations get farther from shore and their number increases, a HVDC grid looks like the most attractive integration option, from both a technical and economical perspective [2][3][4][5]. An agreement on the construction of the so called North Sea Super Grid has already been reached [6] and research on the topic has been initiated [5][7][8].

Meshed HVDC grids have not been built to date, but the topic is ever more relevant for the academic, industrial and political communities, as a consequence of sharp technological improvements for VSC HVDC and ambitious targets for renewable energy integration and interconnection between distant, often asynchronous, grids. A crucial aspect is the fact that future meshed DC grids will most likely be the result of a progressive expansion of the system, rather than a development planned a priori.

One of the technological issues to be addressed if such DC grid is to be built is certainly its control and a number of investigations have touched upon the subject [9][10][11]. The control techniques proposed so far bring about pros and contras and their effectiveness usually depends on the specific application. An integration of the features of the diverse concepts has been realised, resulting in a new active power control method [11]. It can in practice reproduce any of the control techniques suggested and used so far (master-slave, voltage margin, droop,...) and should be adaptable to HVDC converters of different manufacturers.
The control method is especially designed for large meshed DC grids, where control is challenging compared to conventional HVDC systems with a small number of power converters. It has been implemented in with DIgSILENT Power Factory simulation software, while the needed lookup tables have been generated with MATLAB. The validity and effectivity of the undead-band control concept has earlier been shown by simulations for a 3-terminal DC grid test system [11], and it has also been validated on the larger CIGRE B4 DC grid test system [12].

The control strategy is droop based, but the converters have separate control gains for normal and disturbed operation. This way the dead-band for normal operation is avoided and replaced by an undead-band with a control gain which can be small but larger than zero. The control parameters can be optimised for both operating conditions. The undead-band droop can be applied both for DC voltage and AC frequency, but $\mathrm{AC}$ frequency is not treated in this article.

\section{Improved undead-band droop controller}

The general undead-band droop control (described in [11] and [12], basic features recalled in subsection 2.1) is in principle designed to find a steady state operation point after a disturbance of the active power balance.

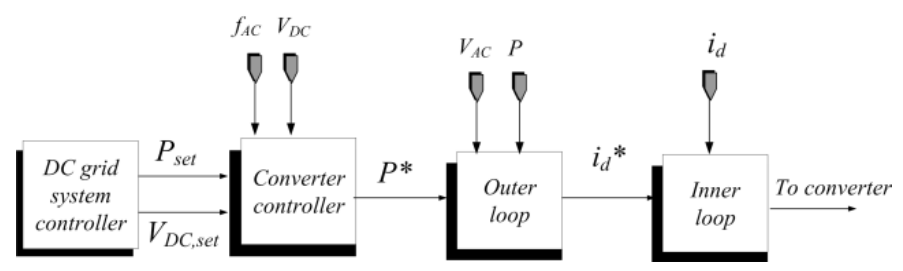

Figure 1: Overall block diagram for undead-band control.

In Figure 1 the generic structure of a single HVDC converter control is depicted. The power and DC voltage set-points are received from a central controller as it happens for other control methods. The other inputs are solely coming from local measurements and therefore avoid any need for fast communication between converters to build the converter power reference. This research mainly regards the converter controller block in Figure 1, where the undead-band droop control is located.

Good results have been achieved in steady state, but now the dynamic design and performance of the control has been 
addressed. In subsection 2.2 the characteristic control curves are smoothened, to reduce undesired effects of non-linearities. In subsection 2.3 the control is priciple is changed from power based coltrol to current based control, to avoid nonlinearity. In subsection 2.4 the control is enhanced for dynamic operation to improve stability.

\subsection{Undead-band droop control}

DC voltage droop control is implemented with the use of an undead-band, where undead means that the droop action is weaker when DC voltages do not deviate substantially from their setpoints, but is still active in order to maintain an efficient and stable control of the grid. When the measured quantities exit such undead-band, the steady-state control gain is increased, leading to a prompter system response.

The control principles are well summarised by Figure 2, showing the $\mathrm{P} / \mathrm{V}_{\mathrm{DC}}$ steady-state curve. The curve illustrates the principle, but does not reflect the control parameters used in the simulations in section 3 .

Other parameters that can be set, according to control objectives and physical limitations, are the limits for power injection and DC voltage.

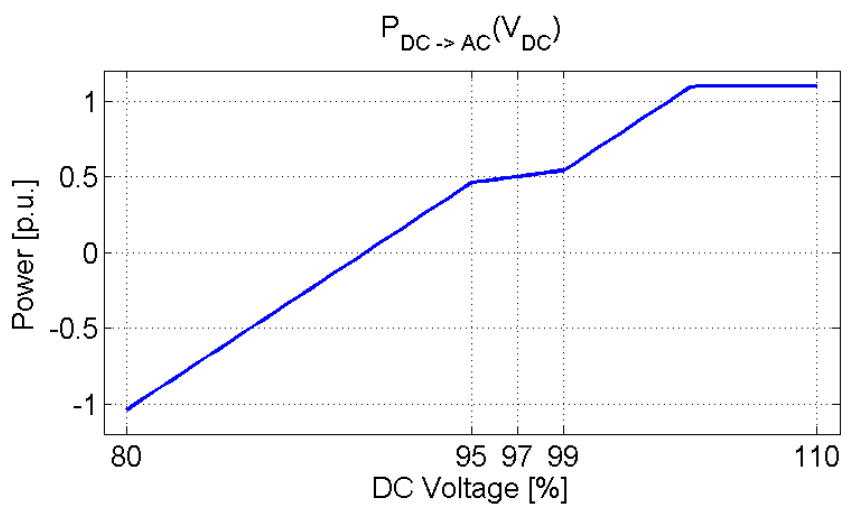

Figure 2: Power - DC voltage relation.

One of the most interesting features of the proposed strategy is the fact that it can in practice reproduce almost any of the control techniques suggested and used so far - e.g. dead-band, master-slave, voltage margin, droop control, etc. This indicates good flexibility of the control structure, where the parameters of every converter can be optimised according to a specific grid's needs.

It is furthermore apparent that efficient decoupling between normal and disturbed operation can be achieved with the proposed control scheme. The control parameters can be optimised for both operating conditions.

Moreover, the expansion to a multi-terminal system, as demonstrated in this article, can easily be done and several kinds of nodes can be accommodated without substantially modifying the control structure.

\subsection{Smooth droop curves}

The droop curves with undead-band as in Figure 2 have sharp edges at the border between normal and disturbed conditions, where the controller switches over from one gain value to another gain value. At this point the controller behaves highly non-linearly, which has significant disadvantages. To mitigate those disadvantages, the droop curves are smoothened with a moving average filter. Therefore the control gain will change progressively from one value to another, when the error exceeds the defined undead-band, rather than jumping to the new value. The smooth control characteristic, which reduces the non-linearity at the borders of the undead-band, is shown in Figure 3.

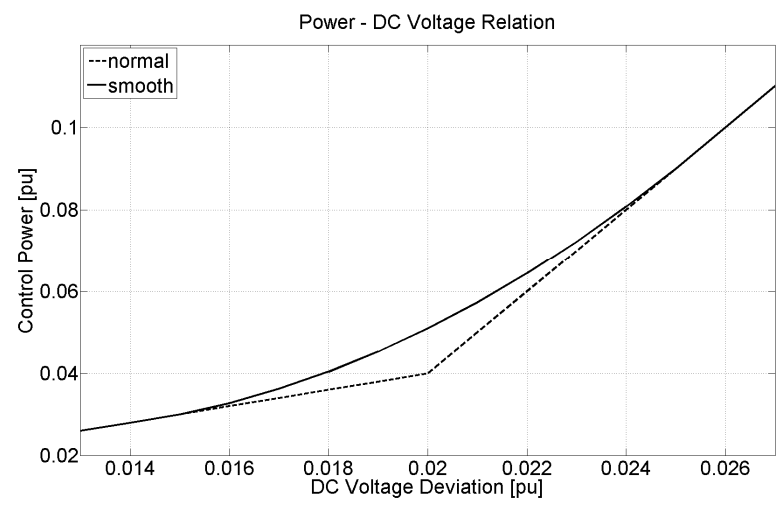

Figure 3: Original characteristic curve and smooth curve.

The width of the moving average filter window has been chosen to $25 \%$ of the undead-band. This has been identified as a good compromise between the conflicting goals of good smoothening (large window) and linear behaviour around the setpoint at small voltage deviations (small window).

\subsection{DC current based DC voltage control}

There are two basic principles how DC voltage can be controlled: Current based control and power based control.

Power based control is a tempting choice, since it is intuitive from a power system perspective, it reminds of powerfrequency control in AC systems, and it easily can be implemented with a PQ-controller. A disadvantage is that power based droop control shows non-linear (hyperbolic) control behaviour.

The main advantage of current based droop control is that it reflects linear control behaviour in the sense that a voltage deviation will result in an equivalent current deviation. As the voltage is linked with charging or discharging the capacitive DC system, the control is linear and is the same for all voltage deviations from the reference value. From a technical point of view current based control can be directly linked with the DC network dynamics: The charging of the capacitances in the DC network relies on a linear voltage-current relation.

It should be considered that the current based droop constant has the physical unit $\Omega$, while the power based droop constant 
would have a physical unit of $1 / \mathrm{A}$ or $\Omega / \mathrm{V}$. This makes current based control more intuitive from a physical perspective.

Therefore the undead-band droop controller has been implemented with current based control, to avoid unnecessary non-linearities.

\subsection{Introduction of separate curves for dynamic control}

If the DC voltage is to be controlled without larger deviations, high control gains are necessary for the controllers. Even though a high gain will give the desired result in steady state, it might lead to dynamic instability and oscillations. The solution chosen in this study to cope with that problem is to introduce separate control characteristic curves for steady state and for dynamic operation. These curves have similar nature, as shown in Figure 2 and smoothened like in Figure 3, but have different control gains. The dynamic control gains have to be limited to values, that don't endanger stability, but the static control gains can be higher.

The two different characteristic curves are applied to two parallel controllers, which receive the measured DC voltage deviation, and give the resulting control action. Those controller output signals are filtered, the dynamic controller with a high pass filter and the static controller with a low pass filter. Those two filtered signal are finally added, and by applying the same time constant to both filters a smooth fadeover from dynamic control to static control can be achieved. The filter time constant has to be chosen considering the resonance frequencies of the oscillations that are to be avoided. In this study a time constant of $50 \mathrm{~ms}$ has been applied. The complete control block diagram looks like Figure 4.

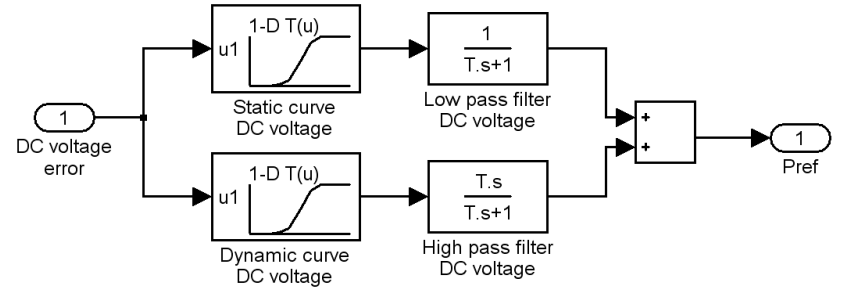

Figure 4: Block diagram of improved undead-band controller.

Using the new improved undead-band controller, the control gain becomes a function of both DC voltage deviation and time. The controller output (control power) is the product of the control gain and the voltage deviation. The relation of control power, DC voltage deviation and time is shown in Figure 5, obtained applying step changes in the DC voltage. The smoothening effect of the moving average filter can be observed, as well as the gain increase over time from the dynamic value to the static value. This applies only outside the undead-band, since within that band, the static gain is low, and no separate dynamic gain is needed.

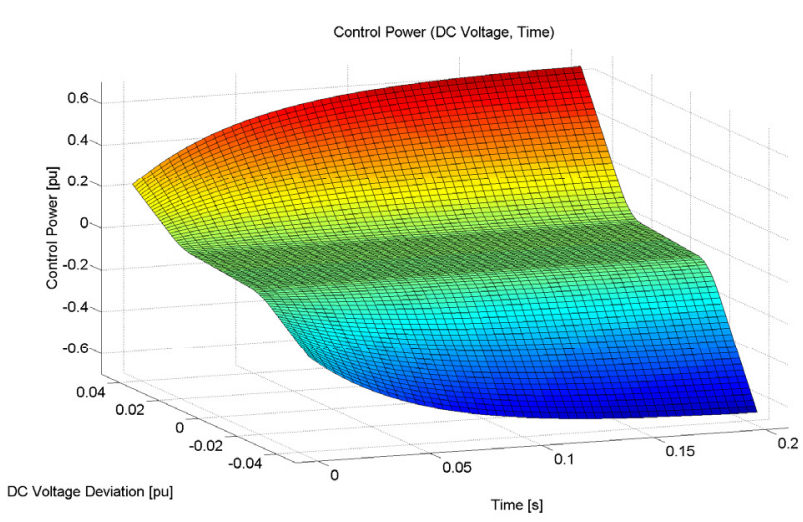

Figure 5: Control power as a function of DC voltage deviation and time.

\section{Simulation results}

Dynamic RMS-type simulations were performed with DIgSILENT PowerFactory to validate the developed improvements for the control strategy with undead-band. The CIGRE B4 DC grid test system, which is under development at the moment, has been implemented for simulations. Even though the test system design is not completely finished yet, the basic layout and some details have been already decided, so the system could be applied in this study. Some brief information about the system is given in [12]. The grid layout is shown in Figure 6.

The system consists of 3 zones. Zone A is producing a power surplus of $1500 \mathrm{MW}$, Zone B is consuming $3900 \mathrm{MW}$ more than it is producing, and the third zone is offshore. The offshore zone is split into 4 asynchronous parts, of which 3 are wind farms with a total generation of $2500 \mathrm{MW}$ and 1 is an offshore load (100MW).

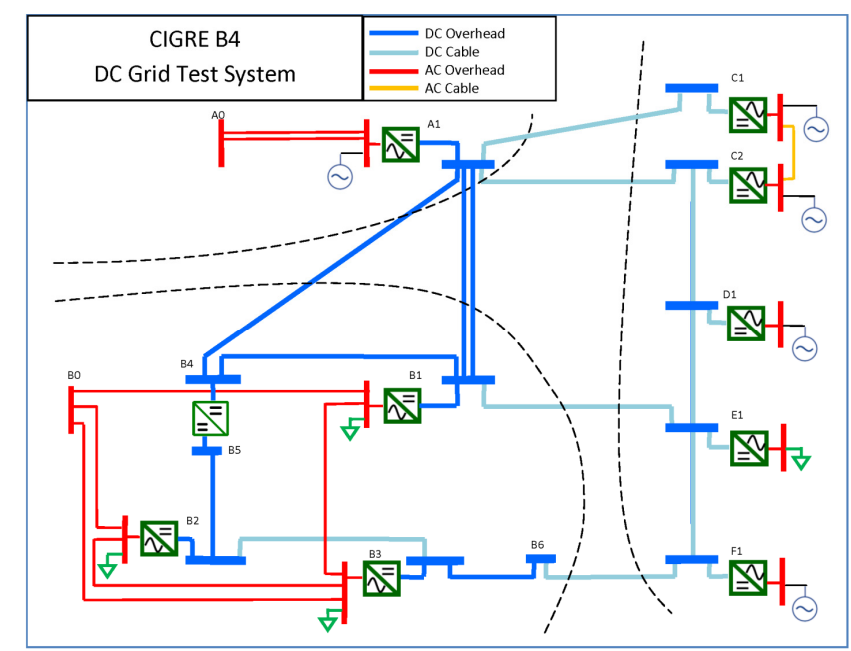

Figure 6: CIGRE B4 DC grid test system.

The undead-band controller has been applied for all four onshore HVDC converters (bus A1, B1, B2 and B3). Four completely different control behaviours of the four converters could be achieved, by simply selecting a different set of control parameters that defines the control behaviour: 
- Converter A1:

DC voltage droop control under normal operation conditions with a high control gain.

- Converter B1:

Proposed undead-band control strategy.

DC voltage droop control under normal operation conditions with a small control gain. A high gain outside the undead-band.

- Converter B2:

Zero control gain, behaves like a constant power source.

- Converter B3:

Regular DC voltage droop control.

The simulated case is an outage of bus D1 (1000MW generation). This is a significant disturbance, since $25 \%$ of the total generation of the DC system is lost, which of course causes the DC voltage to drop (about 3\%).

\subsection{The base case}

The described outage is simulated with the basic controller only. The control power is given in pu while $1 \mathrm{pu}$ refers to 2400MW.

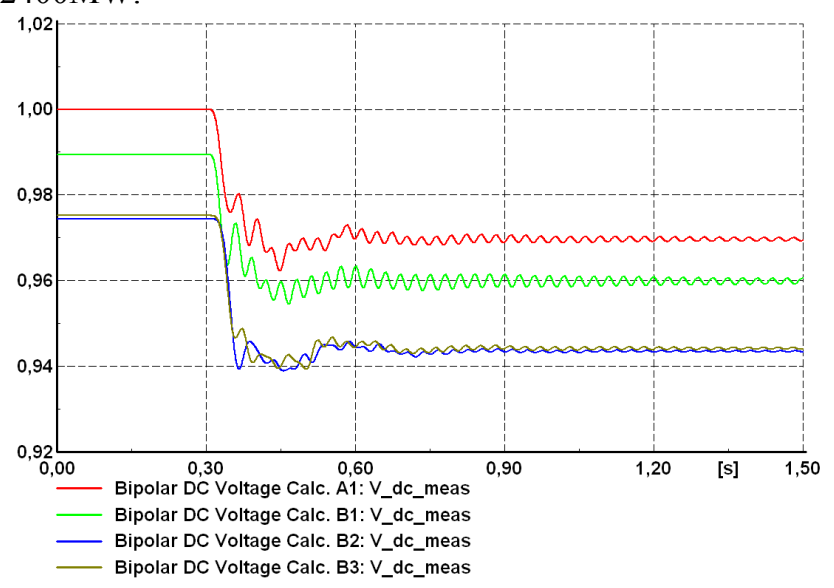

Figure 7: Base case - DC voltage.

The DC voltages at the 4 converter busses are shown in Figure 7. A significant oscillation in the DC voltage can be observed at all 4 busses.

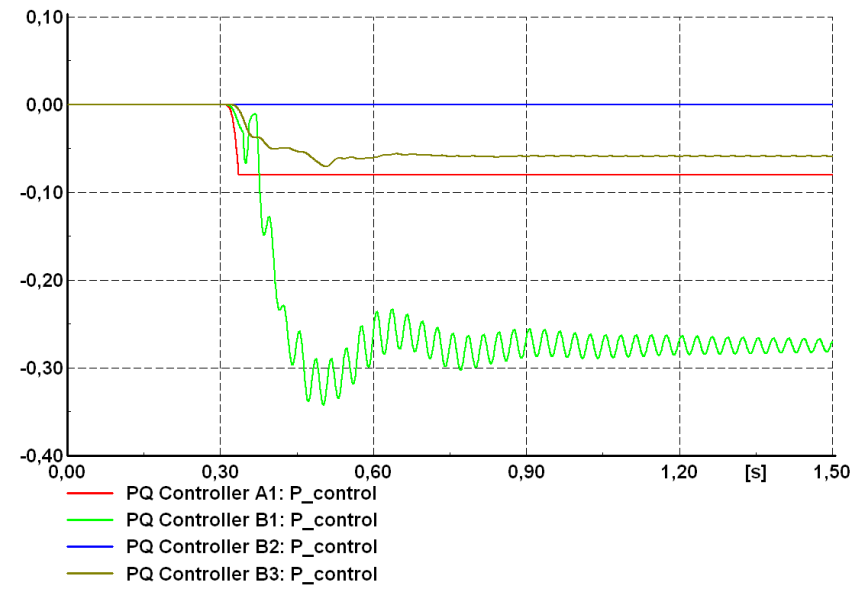

Figure 8: Base case - Controller output.
The four strategies are clearly visible in Figure 8. Converter B2 is operating on constant power. Converter A1 initially absorbs most of the disturbance, but reaches its limitation. Converter B3 is supporting the voltage, but only with a small control gain. Converter B1 carries the main burden, since DC voltage is below the defined undead band, and the control gain is increased significantly.

The voltage oscillation directly causes an oscillation in controller output, especially for converter B1, which operates at a high gain outside the undead-band.

\subsection{The smooth case}

Now the same outage is simulated with the smoothened control curves (see Figure 3).

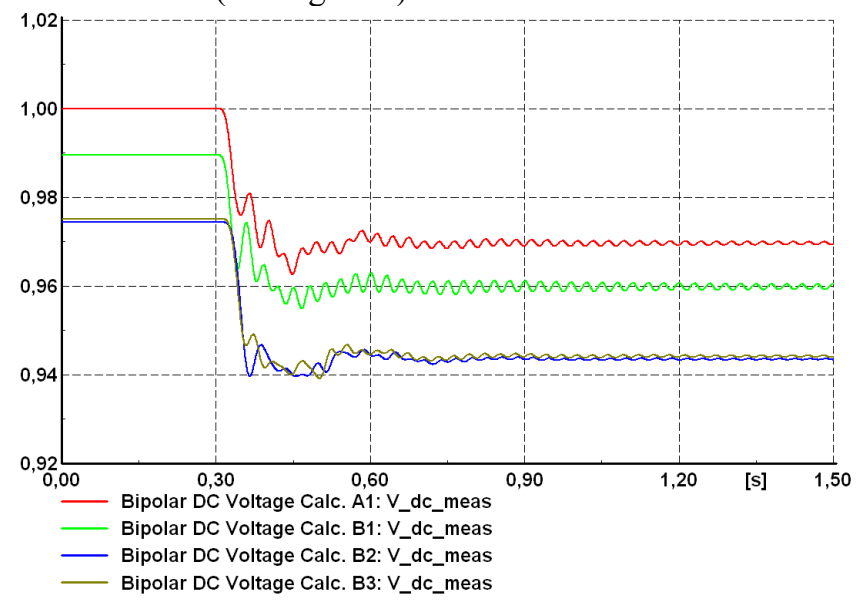

Figure 9: Smooth case - DC voltage.

The DC voltages at the 4 converter busses are shown in Figure 9. The oscillation in the DC voltage can still be observed.

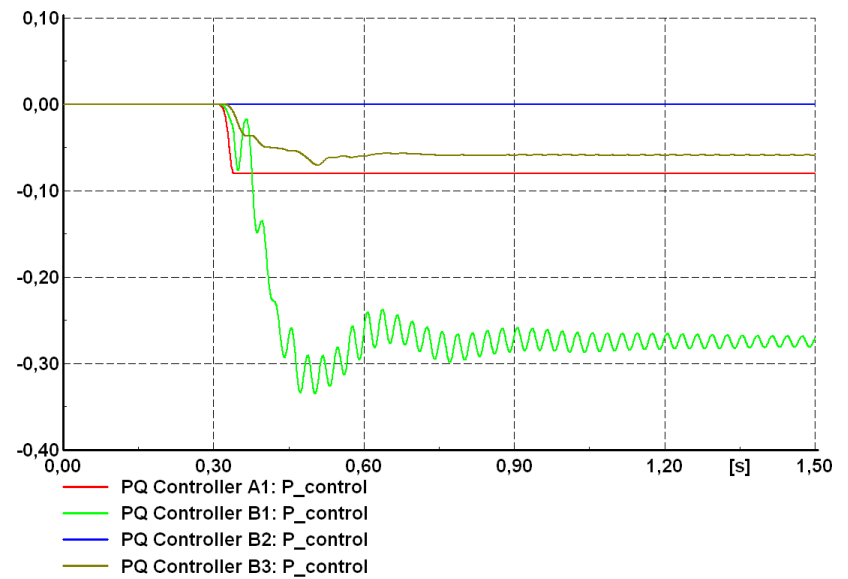

Figure 10: Smooth case - Controller output.

The controller output is shown in Figure 10. The problematic oscillation from Figure 8 is still present, but is reduced slightly. 


\subsection{DC current based control}

Now DC voltage control is changed from power based control to current based control, and the simulation is repeated. Again, the smoothened control curves are applied.

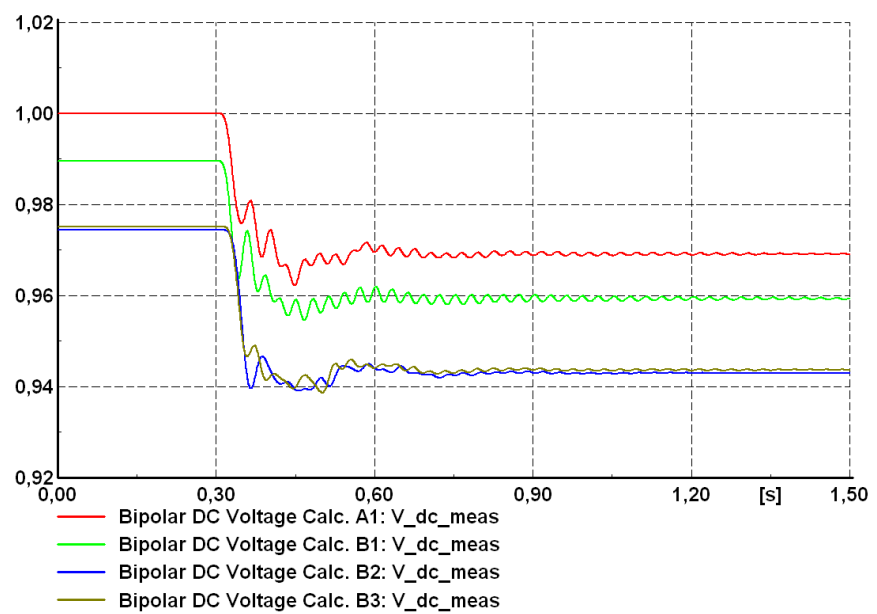

Figure 11: DC current based control - DC voltage.

The DC voltages at the 4 converter busses are shown in Figure 11. The oscillation in the DC voltage can still be observed, but disappears mostly within a second.

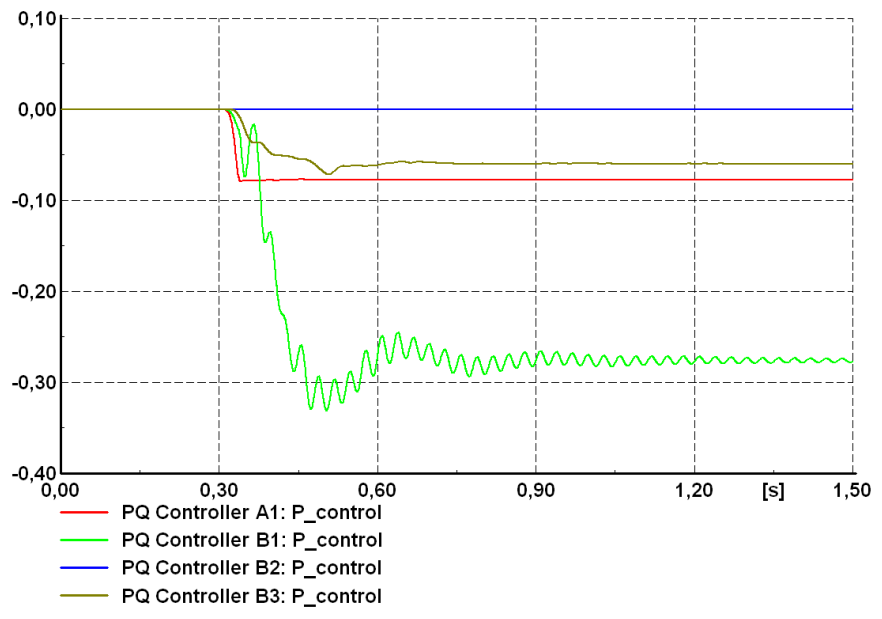

Figure 12: DC current based control - Controller output.

The controller output is shown in Figure 12. The problematic oscillation from Figure 10 is still present, but fades out similar to the DC voltage oscillation.

\subsection{Separate dynamic gain}

Now the same outage is simulated with an additional separate dynamic control gain. Again, the smoothened control curves and DC current based control are applied.

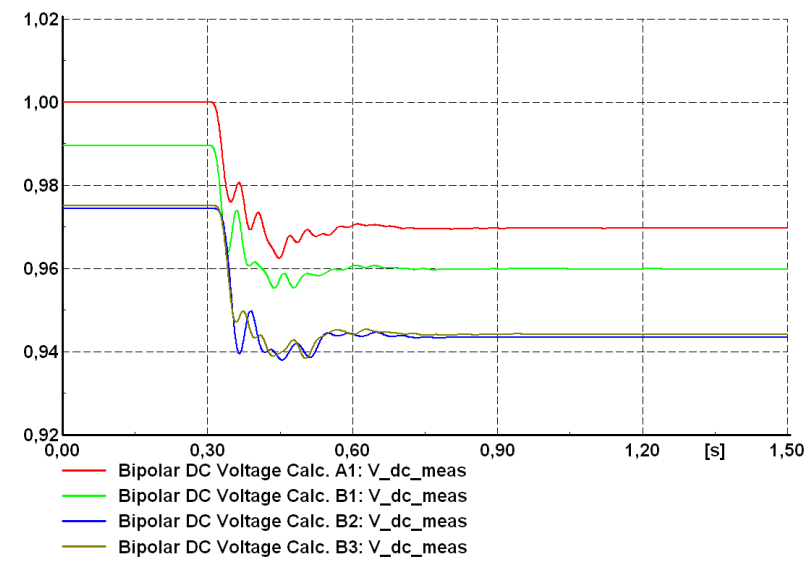

Figure 13: Separate dynamic gain - DC voltage.

The DC voltages at the 4 converter busses are shown in Figure 13. The oscillation in the DC voltage can initially be observed, but disappears in less than half a second. This indicates that the oscillation is started by the outage but maintained by the HVDC converters with inappropriate controllers.

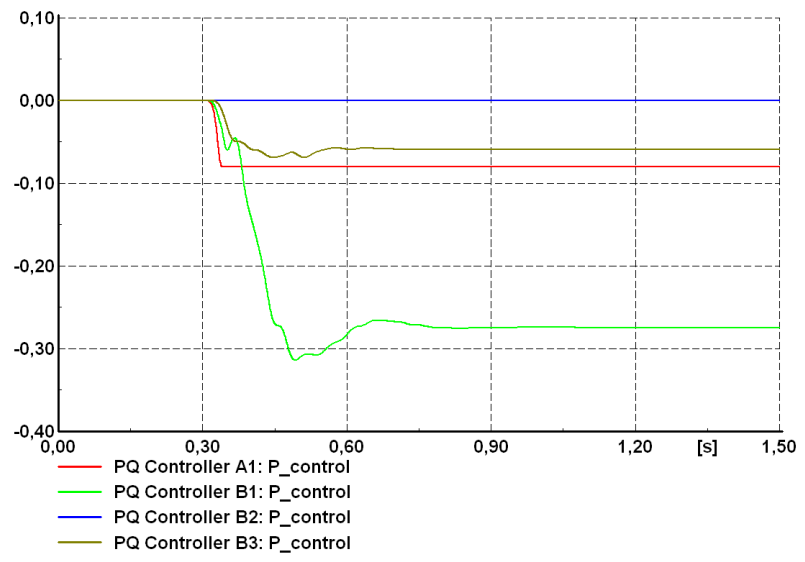

Figure 14: Separate dynamic gain - Controller output.

The controller output is shown in Figure 14. The oscillation is significantly reduced, because the dynamic controller of B1 is not reacting with high gain on that oscillation. 


\section{Conclusion}

A new active power control method for HVDC converters, especially designed for large meshed DC grids, has been developed and published in [11]. The control has been implemented in with DIgSILENT Power Factory simulation software, while the needed lookup tables have been generated with MATLAB. The validity and effectivity of the undeadband control concept has earlier been shown by simulations for a 3-terminal DC grid test system [11], and it has also been validated on the larger CIGRE B4 DC grid test system [12].

The control strategy is droop based, but the converters have separate control gains for normal and disturbed operation. This way the dead-band for normal operation is avoided and replaced by an undead-band with a control gain which can be small but larger than zero. A significant advantage of the control concept is that various different control behaviours can be achieved by choosing the parameters correctly. Therefore it is not only a new control strategy, but can also serve as a framework, which includes many existing control strategies.

Now the dynamic performance of the control has been optimised and is described in this article.

The first issue addressed is, that any droop curve with deadband or undead-band has sharp edges at the limits of the band and is therefore highly non-linear at those points, which may cause and/or worsen undesired oscillations. This problem has been solved by applying a moving average filter upon the droop curves, removing the sharp edges. This can of course not remove the non-linearity (which actually is desired) but it makes linear approximation possible in any point of the curve (not possible for unfiltered curves with edges). Therefore the moment when the limit of the undead-band is reached does not cause a step change in the control behaviour, which would otherwise excite and/or amplify oscillations.

The second issue addressed is, that current based droop control is better than power based droop control. This can be expected, since current based voltage droop control is linear, and the droop constant has the physical unit Ohm. Power based voltage droop control is non-linear. Simulations have shown that the choice is relevant for dynamic performance.

The third issue addressed is, that high control gains, which may be desired for realising a good operation point, can on the other hand lead to further dynamic instability and oscillations. Therefore two separate gains have been introduced, for static and dynamic operation. The static gain can be as high as desired, but the dynamic gain is limited by system stability. A combination of high pass filter and low pass filter achieves a smooth fade over from the dynamic to the static gain, where the time constant has to be chosen regarding the system modes.

The most significant improvements have been achieved by reducing the dynamic gain, a finding which is not surprising.
Still, the authors would like to highlight, that any nonlinearities do influence the system dynamic performance, and they should be avoided or reduced.

\section{Acknowledgements}

The authors would like to thank the OffshoreDC consortium, funded by Nordic Energy Research, for initiating the cooperation, which resulted in this article.

We also would like to thank the Centre for renewable energy (SFFE) for funding travel and research visit to DTU Risø Campus, which made this cooperation work possible.

Special thanks also to the members of CIGRE B4 for their contribution to the CIGRE B4 DC grid test system.

\section{References}

[1] T.K. Vrana, O.B. Fosso, "Technical Aspects of the North Sea Super Grid", CIGRE Electra, November 2011.

[2] "Trade Wind", final report, EU-IEE project, 2009. www.trade-wind.eu

[3] "Offshore Grid Development in the North Seas: ENTSOE views", 2011. www.entsoe.eu

[4] "Roadmap to the deployment of offshore wind energy in Central and Southern North Sea to 2030", final report, EU-IEE project Windspeed, March 2011. www.windspeed.eu

[5] J. de Decker, P. Kreutzkamp, others, "OffshoreGrid: Offshore Electricity Infrastructure in Europe", final report, EU-IEE project OffshoreGrid, October 2011. www.offshoregrid.eu

[6] "Political declaration on the North Seas Countries Offshore Grid Initiative" Council of the European Union, December 2009. www.consilium.europa.eu

[7] L. Zeni, T. Haileselassie, G. Stamatiou, A. Geisler Eriksen, J. Holbøll, O. Carlsson, K. Uhlen, P. Sørensen, N. Cutululis, "DC grids for integration of large scale wind power", EWEA Offshore Conference, Amsterdam, 2011.

[8] www.islesproject.eu

[9] T. Nakajima, S. Irokawa, "A control system for HVDC transmission by voltage sourced converters" Power Engineering Society Summer Meeting, IEEE, volume 2, pages 1113-1119, 1999.

[10] B.K. Johnson, R.H. Lasseter, F.L. Alvarado, R. Adapa, "Expandable multiterminal dc systems based on voltage droop", IEEE Transactions on Power Delivery, 8(4):1926-1932, 1993.

[11] T.K. Vrana, L. Zeni, O.B. Fosso, "Active Power Control with Undead-Band Voltage \& Frequency Droop for HVDC Converters in Large Meshed DC Grids", EWEA Conference, Copenhagen, April 2012.

[12] T.K. Vrana, L. Zeni, O.B. Fosso, "Active Power Control with Undead-Band Voltage \& Frequency Droop Applied to a Meshed DC Grid Test System", IEEE Energycon, Firenze, September 2012. 